\title{
Second-order conditioning of the pigeon's keypeck
}

\author{
MICHAEL E. RASHOTTE, ROBERT W. GRIFFIN, and CHERYL L. SISK \\ Florida State University, Tallahassee, Florida 32306
}

\begin{abstract}
Pigeons learned to peck a keylight (S2) when it was paired with a stimulus (S1) that already evoked keypecking. Control procedures showed that S2 acquired control over responding because it was paired with S1 and because S1 had a conditioning history, thereby supporting the claim that S2 was a second-order conditioned stimulus. Second-order conditioning occurred as rapidly when S1 was a keylight as when it was a tone. Test procedures showed that after second-order conditioning, responding to S2 was markedly debilitated by the extinction of responding to S1, indicating that the ability of S2 to evoke a response importantly depends upon the continued ability of S1 to do so. Our demonstration that directed motor action in the pigeon is susceptible to second-order conditioning suggests a new interpretation of conditioned reinforcement in instrumental learning. Our demonstration that the effectiveness of S2 depends upon the continued effectiveness of S1 indicates that $\mathrm{S}-\mathrm{S}$ associations are formed in this version of the second-order conditioning experiment.
\end{abstract}

In conditioning the alimentary and defensive reflexes of dogs, Pavlov noted that distinctive secretory and motor components of each reflex were evoked by the conditioned stimulus (Pavlov, 1927, Lecture II). He emphasized the secretory component because it was more susceptible to accurate measurement and less susceptible to anthropomorphic interpretation. In recent years, the discovery of autoshaping (Brown \& Jenkins, 1968) has focused attention on directed motor responses evoked by classically conditioned stimuli, and automated measurement has attenuated the difficulties Pavlov enumerated in studying motor behavior. In a typical autoshaping experiment, hungry pigeons approach and contact a localized stimulus such as a lighted response key which signals presentations of food. There seems little doubt that this directed motor behavior provides a behavioral index of the associative status of the localized stimulus (Hearst \& Jenkins, 1974) and, consequently, autoshaping provides a new experimental methodology for examining some old questions about associative learning.

Autoshaping has been demonstrated with the method of first-order classical conditioning in which a neutral stimulus (S1) acquires control over

This research was supported in part by NIMH Training Grant MH-11218. Experiments 1 and 2 were reported at the 1974 meeting of the Psychonomic Society and Experiments 3 and 4 were reported at the 1975 meeting. Experiments 3 and 4 are based on a thesis by C.L.S. which fulfilled part of the requirements for the MS degree at Florida State University, March, 1976. The authors wish to thank Patricia Green and Daniel Gokey for help in running some of the animals. Reprints may be obtained from Michael E. Rashotte, Department of Psychology, Florida State University, Tallahassee, Florida 32306. R. W. Griffin is now at the Gaines Nutrition Center, Kankakee, Illinois. approach and contact responses because it signals a biologically significant event such as food or water. The first experiment in the present paper demonstrates that the pigeon's keypeck can be autoshaped with the method of second-order conditioning in which a neutral stimulus (S2) acquires control over keypecking solely because it signals presentations of $\mathrm{Sl}$, a first-order conditioned stimulus (cf. Pavlov, 1927, Lecture III). This demonstration is important because it extends the empirical base of secondorder conditioning to include directed motor action, it implicates classical conditioning in the control of directed motor behavior in a wider range of situations than has been acknowledged (Hearst \& Jenkins, 1974; Moore, 1973), and because it offers a new opportunity to test the generality of conclusions about the nature of associative processes in secondorder conditioning (Rescorla, 1973a). These issues are discussed more fully in the presentation of the following experiments.

\section{EXPERIMENT 1}

Experiment 1 provides a well-controlled demonstration of second-order conditioning of the pigeon's keypeck. In the first part of the experiment, a white key light (S1) became a first-order conditioned stimulus that evoked keypecking through S1-grain pairings. Then, with first-order conditioning continuing in alternate sessions, a blue key light (S2) was paired with $\mathrm{S} 1$ in second-order sessions. The acquisition of control over keypecking by S2 during these sessions provides the basic demonstration of second-order conditioning of the pigeon's keypeck. Before such a demonstration can be considered valid, however, it must also be demonstrated that S2 evoked keypecking because of the S2-S1 pairings, 
otherwise responding to $\mathrm{S} 2$ could not be attributed to associative processes, and that $S 1$ required a conditioning history, otherwise keypecking to S2 would simply be an instance of first-order conditioning. The present experiment included groups to assess these possibilities.

\section{METHOD}

\section{Subjects}

Twelve experimentally naive White Carneaux pigeons, 6-12 months old, were maintained at $80 \%$ of their free-feeding weights, and were individually housed under constant fluorescent lighting. Water and grit were always available in the home cages.

\section{Apparatus}

Three identical test chambers of the sort described by Ferster and Skinner (1957) were employed. The chambers, which measured $40 \times 37.5 \times 19.4 \mathrm{~cm}$, were painted flat black and were enclosed in slightly larger wooden boxes. A clear plastic pigeon key was mounted behind a $2.5-\mathrm{cm}$-diam hole located $25.4 \mathrm{~cm}$ above the grid floor and $6.4 \mathrm{~cm}$ to the left of center on one wall. Pecks on the key with a minimum force of $0.28 \mathrm{~N}$ were electronically recorded as key contacts. Various colors were rear-projected onto the key by applying $28 \mathrm{~V}$ ac to No. 1820 bulbs in an in-line projector equipped with Wratten filters. Grain was presented by raising a hopper to an opening $(5.1 \times 5.7 \mathrm{~cm})$ centered on the keywall, the bottom edge of the opening $10.2 \mathrm{~cm}$ above the floor. The opening was illuminated by a recessed white bulb whenever the hopper was raised. A closed-circuit television camera was mounted in the ceiling of each test chamber, and houselight illumination was provided by a $100 \mathrm{Vac} 25$-W frosted incandescent bulb recessed in the ceiling opposite the keywall. Extraneous sounds were masked by white noise $\left(80 \mathrm{~dB}\right.$ re $\left.20 \mu \mathrm{N} / \mathrm{m}^{2}\right)$ delivered continuously through a $10.2-\mathrm{cm}$ 4-ohm speaker mounted behind the keywall in each chamber, and by a white-noise source in the experimental room. An exhaust fan in each chamber provided ventilation and additional masking noise. Television monitors and electromechanical control and recording equipment were located in an adjoining room.

\section{Procedure}

Preliminary training. All groups received two daily sessions in which the unconditioned tendency to peck Sl was assessed. The chamber was dark before and after each session, and S1, a 6-sec white key light, was presented 30 times at 120-sec intertrial intervals (ITI). Magazine training began in the third session when the pigeons were placed in the illuminated chamber with the hopper raised and overflowing with grain. After the pigeon ate for about $30 \mathrm{sec}$, the hopper was lowered briefly and, across successive hopper presentations, the time the hopper was available was gradually decreased to $4 \mathrm{sec}$, and the time it was unavailable was gradually increased to about $60 \mathrm{sec}$. Magazine training continued for each pigeon until it reliably approached and ate with a short latency when the hopper was raised. This required two or three sessions.

First-order conditioning. In each of the next 20 daily sessions, all pigeons received 30 presentations of the 6-sec white key light (S1) and $304-\mathrm{sec}$ hopper presentations. S1 was established as a first-order conditioned stimulus in two groups of four pigeons which received forward pairings of $S 1$ and grain during these sessions. These groups were designed P-P and P-R, the first letter, $P$, signifying that $S 1$ and grain were paired during first-order conditioning. The second letter in each group designation refers to the second-order conditioning procedure to be described later. The third group, $\mathrm{R}-\mathrm{P}$, received $\mathrm{Sl}$ and grain in a quasi-random sequence to prevent $\mathrm{Sl}$ from acquiring associative strength while equating the number of exposures to $\mathrm{S} 1$ and grain with the other groups (cf. Rescorla, 1967). For Groups P-P and P-R, each presentation of S1 was followed immediately by access to grain, the ITI was $120 \mathrm{sec}$, and the response key was dark during both the ITI and grain presentation. For Group R-P, SI was presented every $120 \mathrm{sec}$ and grain was presented according to a repeating irregular sequence of 15 different intervals geometrically distributed around a mean value of $120 \mathrm{sec}$ (Fleshler \& Hoffman, 1962). The sequence was entered at a randomly chosen point for each pigeon on each day. The only constraint on the scheduling of events for Group R-P was that $\mathrm{Sl}$ and grain presentations could not overlap. The chamber was dark before and after each session, and the houselight was constantly illuminated while the session was in progress. Sessions were terminated after the 30 th grain presentation for Groups P.P and P-R and after the 60th event for Group R.P. The behavior of the pigeons had no effect on the temporal distributions of $\mathrm{Sl}$ and grain.

Second-order conditioning. All groups continued to receive daily sessions, with second-order conditioning in odd-numbered sessions (Sessions $21,23, \ldots$ ) and first-order conditioning, as described above for each group, in even-numbered sessions (Sessions 22, 24, . . . ). Grain was never presented in second-order sessions. In the initial second-order sessions, a 6-sec blue key light (S2) was presented 10 times alone at a 120 -sec ITI to assess the strength of keypecking evoked by $\mathrm{S} 2$ before $\mathrm{S} 2-\mathrm{S} 1$ pairings began. A minimum of two S2-alone sessions and a criterion of one session with no rated pecks (see next section on dependent variables) directed towards $\mathbf{S} 2$ was met by all but one pigeon in Group P.P, which received six $\mathbf{S} 2$-alone sessions and made one rated peck in each of Sessions 5 and 6 . In the next four second-order sessions, S2 and S1 each were presented 10 times. Groups P-P and R-P received forward pairings of $S 2$ and $S 1$ at a 120 -sec ITI, with each S2 presentation followed immediately by S1. For Group P-R, however, the stimuli were presented in a quasi-random sequence in which S2 occurred every $120 \mathrm{sec}$ and S1 occurred at variable intervals averaging $120 \mathrm{sec}$ (Fleshler \& Hoffman, 1962). The only constraint on the scheduling of events for Group P-R was that $S 2$ and $S 1$ could not overlap. A valid demonstration of second order conditioning requires that $S 2$ acquire control over keypecking in Group P.P but not in Groups R-P or P-R. Group P-P has an S1 with associative strength and has S2-S1 pairings, both assumed necessary for second-order conditioning; S1 should have no associative strength in Group $\mathrm{R}-\mathrm{P}$, and $\mathrm{S} 2-\mathrm{S} 1$ pairings are lacking in Group P-R. The chamber was dark before and after each second-order session, and the houselight was illuminated continuously while the sessions were in progress. The behavior of the pigeons had no effect on the scheduled presentations of S2 and S1.

Dependent variables. Acquisition of responding was measured for each pigeon by the number of trials pricr to the first trial with a response ("key contact," see below) in first-order and in secondorder sessions. In addition, a sustained-responding measure of acquisition was made in second-order conditioning: the number of trials prior to three out of four successive trials with a response.

Two response measures were computed in each first-order session: the percentage of trials (i.e., Sl presentations) on which each pigeon pecked the key with sufficient force to close the microswitch at least once, and the rate of keypecking during trials (total keypecks during $\mathrm{S} 1 /$ total $\mathrm{S} 1$ time). Because these measures require the pigeon to contact the key, they will be referred to as "key-contact" measures. In second order sessions, four key-contact measures were computed: the percentages of S2 and S1 presentations with at least one keypeck, and the rates of keypecking while S2 and S1 were present on the key. In all second-order sessions, pecking movements towards S1 and S2 were rated by observers so that the percentages of S1 and S2 presentations on which at least one "rated peck" occurred could be computed. Rated pecks were scored by two observers who watched every stimulus presentation on television monitors and scored a pecking movement whenever the pigeon thrust its beak towards the lighted key and then retracted it to approximately the starting position. A rated peck was scored whether or not the pigeon's movements resulted in a key contact, so the ratedpecks measure is the sum of all pecking movements directed towards the conditioned stimuli and includes off-key pecks which 
sometimes occur in autoshaping experiments (e.g., Barrera, 1974). Interobserver reliability in scoring rated pecks was virtually perfect, and on the few trials when a discrepancy occurred, the trial was scored as showing no pecking movement to insure a conservative estimate of responding in the rated-pecks measure. Rated pecks were scored in the same way in all experiments reported in this paper, except that only one observer was employed in Experiments 3 and 4 and reliability checks were made with two observers on several occasions. In some experiments, rated pecks were scored in first-order sessions, as noted in the text. Data presentation in this paper will emphasize two measures: percent trials with a key contact and percent trials with a raied peck. The rate-of-keypecking measure generally showed the same effects as the other measures, but was more subject to variability because of off-key pecking.

\section{Results and Discussion}

None of the pigeons pecked the response key when Sl was presented alone during preliminary training, but, in Groups P-P and P-R, S1 rapidly gained control over keypecking when S1-food pairings began. In the 20th first-order session, all pigeons in both groups contacted S1 on $100 \%$ of the trials and the mean rates of keypecking were 93.3 and $89.3 \mathrm{pecks} / \mathrm{min}$ for Groups P-P and P-R, respectively. In Group R-P, S1 failed to gain control over keypecking during the 20 sessions in which S1 and grain were presented in a quasi-random sequence. Only one pigeon ever pecked at the response key in this group, and that was a nonassociative peck, since it occurred the first time S1 was presented after magazine training. Frequent observations indicated that there was no offkeypecking during $\mathrm{S} 1$ presentations by pigeons in Group R-P; the most common behavior observed in this group was pacing back and forth along the keywall. Thus, before second-order conditioning began, S1 was an effective first-order conditioned stimulus for keypecking in Groups P-P and P-R, but not in Group R-P.

Figure 1 summarizes the percent trials with at least one response in successive second-order conditioning sessions. Each data point is an average across all pigeons in each group, except in Group P-P, for which one pigeon's data was not included. The performance of that pigeon will be discussed later. The first two points in the upper panels show that responding was low when $\mathbf{S 2}$ was presented alone in the two sessions immediately before S2-S1 pairings began. Not surprisingly, none of the pigeons in Group R-P pecked when S2 was first presented, and, because a minimum of two sessions was required, Figure 1 shows all S2-alone sessions for that group. All pigeons in the other groups pecked S2 when it was first presented, but not as strongly as they pecked $\mathrm{S} 1$ in first-order sessions, indicating stimulus generalization between the blue-light $\mathrm{S} 2$ and the white-light S1. The mean percent trials with a key contact in the first S2-alone session was 53.3 for Group P-P and 37.7 for Group P-R. In the immediately preceding first-order session, these

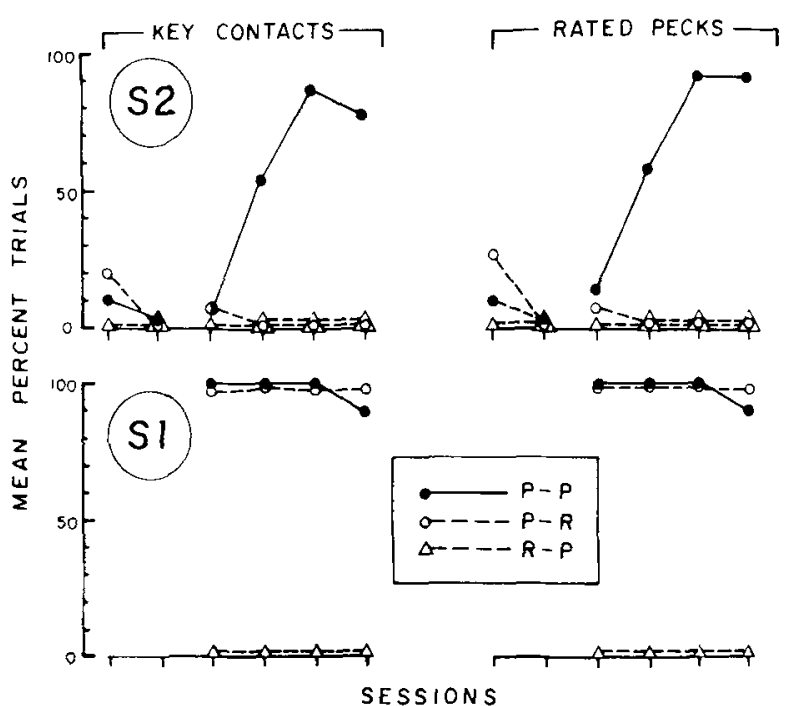

Figure 1. Mean percent trials with a key contact and rated peck on S2 and S1 in second-order conditioning sessions for each group in Experiment 1. (See text for details.)

groups contacted S1 on $100 \%$ of trials. Group P-P had a mean of five S2-alone sessions before S2-S1 pairings began; the mean for Group P-R was 2.3.

The last four data points in each of the upper panels show that $\mathrm{S} 2$ came to control pecking only when it was paired with an S1 which itself controlled pecking (Group P-P). The first key contact on S2 occurred after a mean of $10 \mathrm{S2-S1}$ pairings for Group P-P, and the first sustained run of responding to S2, measured as the first three out of four successive $\mathbf{2} 2$ trials with a contact, occurred after a mean of 14 S2-S1 pairings. In first-order conditioning, Group P-P required a mean 11 pairings of S1 and grain to achieve the first key contact. These data suggest that the pigeon's keypeck is acquired at approximately the same rate in first- and secondorder conditioning.

Once acquired, keypecking to S2 occurred on a high percentage of trials in the remaining secondorder sessions. The function shown for Group P-P in Figure 1 is representative of individual pigeons in that group. Another index of the strength of responding established to $\mathrm{S} 2$ is that the mean rate of keypecking was 79.7 pecks $/ \mathrm{min}$ in the last secondorder conditioning session for Group P-P.

The acquisition of keypecking to S2 in Group P-P provides a convincing demonstration of second-order conditioning of the pigeon's keypeck because the other groups show that S2 needs to be paired with S1 (Group P-R) and that S1 needs to be paired with food (Group R-P) for acquisition to occur. These are the findings necessary for a well-controlled demonstration of second-order conditioning. The rated-pecks data in the upper right panel of Figure 1 confirm that $S 2$ failure to acquire control over pecking in Groups P-R and R-P. Those data rule out the possibility that $S 2$ acquired control over 
pecking in these groups but that the pecks evoked by $\mathrm{S} 2$ were not sufficiently forceful to activate the response key, or were primarily off-key pecks. The similarity of the key-contact and rated-pecks data for Group P-P indicates little off-key pecking to S2 in that group.

The bottom panels of Figure 1 show that S1 strongly evoked pecking in second-order sessions for Groups P-P and P-R, but not for Group R-P. These data indicate that the between-group differences in keypecking to $\mathrm{S} 1$ found in the 20th first-order conditioning session were maintained virtually unchanged throughout second-order conditioning.

One pigeon in Group P-P was not included in Figure 1 because it responded to both $S 2$ and $S 1$ in a different manner than the other pigeons in that group. This pigeon failed to peck S2 and, across the four second-order sessions in which S2-S1 pairings occurred, showed a pronounced decrease in the strength of responding to S1. Responding to S1 remained strong in first-order conditioning sessions which alternated with second-order sessions, however, so that S2 appeared to become a conditioned inhibitor (Pavlov, 1927, Lecture V) for this pigeon rather than a second-order conditioned stimulus. This "inhibitory" pattern of responding to S2 and S1 has been found in some other pigeons (see Experiment 2), but tests needed to determine whether S2 is truly inhibitory in these cases (Rescorla, 1969) have not been carried out. It has been obvious since Pavlov's time that second-order conditioning and conditioned inhibition are established with procedures that are similar, if not identical. Later experiments in this paper indicate that our methodology yields a relatively few cases in which $\mathrm{S} 2$ appears to become inhibitory (cf. Razran, 1955).

In summary, the present experiment shows that the pigeon's keypeck comes to be evoked by a stimulus that is paired with a first-order conditioned stimulus, and appropriate control groups indicate that this is a valid demonstration of second-order conditioning. This finding is significant for three reasons. First, it shows unequivocally that directed motor action is susceptible to second-order conditioning and, thereby, adds to the growing number of recent demonstrations that second-order conditioning is a robust phenomenon (e.g., Holland \& Rescorla, 1975a, b; Rizley \& Rescorla, 1972). Second, it suggests that classical conditioning might account for at least some strengthening of motor responding in instrumental training situations which usually is attributed to conditioned reinforcement. Just as firstorder classical conditioning might account for the response-strengthening effects of instrumental reinforcement when contingencies are arranged between motor response and reinforcers such as food and water (Moore, 1973), second-order conditioning might account for the strengthening of motor responses when contingencies are arranged between responses and conditioned "reinforcers" (i.e., "stimuli"). The response-reinforcer contingency may be effective in both cases because it insures that certain neutral stimuli in the environment (e.g., response key) are paired with a stimulus (conditioned or unconditioned) which evokes responses similar to those specified by the instrumental contingency. The logic of this argument has been fully developed for first-order conditioning by Moore (1973), and its extension to second-order conditioning is discussed more fully in the general discussion of this paper. Third, the present experiment provides a new methodology for investigating the nature of associative processes in second-order conditioning, and it is this question which is addressed in the remaining experiments in this paper.

\section{EXPERIMENT 2}

Rescorla (e.g., 1973a) has concluded that an S-S association between the conditioned stimulus (CS) and the unconditioned stimulus (US) is established in first-order conditioning, whereas an S-R association between $\mathrm{S} 2$ and the response evoked by $\mathrm{S} 1$ is established in second-order conditioning. This conclusion is based on a series of experiments which follow Rozeboom's (1958) prescription for determining what is learned during conditioning. Rozeboom proposed that three-stage experiments be designed in which, in the case of first-order conditioning, CS and US are paired in Stage 1 until CS evokes a conditioned response (CR). In Stage 2, CS-US pairings are discontinued and some manipulation is performed to change the response evoked by US. In Stage 3, CS is presented again to determine what $C R$ it evokes.

Rozeboom discussed three possible outcomes of such experiments and the implications of each for an associative interpretation of conditioning. One outcome is that, in Stage 3, CS evokes the same CR it evoked in Stage 1. This outcome indicates that after conditioning, the ability of CS to evoke CR is independent of the current status of US, implying that an S-R association had been formed between $\mathrm{CS}$ and the original response evoked by US. A second outcome is that CS evokes the new response established to US in Stage 2. This outcome would imply that CR occurs because of an S-S association between CS and US: the CS evokes whatever response is currently evoked by US. The third outcome is that some elements of both the original CR and the response established to US in Stage 2 occur, implying a composite associative structure with both S-S and S-R components.

Rescorla's experiments have consistently shown that after first-order conditioning, manipulations which change the effectiveness of US in Stage 2 also 
change the effectiveness of CS in Stage 3. After second-order conditioning, however, changes in the effectiveness of S1 in Stage 2 have no effect on the ability of S2 to evoke the original CR in Stage 3 (Holland \& Rescorla, 1975a, b; Rescorla, 1973a, b; Rizley \& Rescorla, 1972). According to the above logic, these findings support the conclusion that S-S associations underlie first-order conditioning while S-R associations underlie second-order conditioning (Rescorla, 1973a). Furthermore, Konorski's (1948, p. 107) proposal that second-order conditioning may involve an S-S association between S2 and the neural representation of US (which is presumably evoked by $\mathrm{S} 1$ on each second-order conditioning trial) has been tested in Rescorla's experiments by changing the effectiveness of US (rather than S1) in Stage 2 of a second-order conditioning experiment. Rescorla (1973b) found that S2 continued to evoke the original CR in Stage 3, thereby rejecting Konorski's hypothesis.

The present experiment investigated whether the conditioned effectiveness of S2 was independent of the conditioned status of $\mathrm{Sl}$ in the autoshaping version of the second-order conditioning experiment. Keypecking was established to S2 in three groups of pigeons with the procedures employed for Group P-P in Experiment 1. Then, in the second stage of the experiment, successive first-order conditioning sessions were given in which keypecking to S1 was eliminated in two groups either through extinction, in which S1 was presented without grain (Group P-P-E), or through presentations of a quasirandom sequence of $\mathrm{Sl}$ and grain (Group P-P-R). Keypecking to $S 1$ was maintained in the other group (P-P-P) through continued pairings of S1 with grain. In the third stage of the experiment, S2 and S1 were presented in a single test session to evaluate the ability of each of these stimuli to evoke keypecking. It was expected that all groups would respond to S2 at an equivalent level in Stage 3 if an S-R association had formed between $S 2$ and the response evoked by $\mathrm{S} 1$ during second-order conditioning (Rescorla, 1973a). Furthermore, two methods of eliminating responding to S1 were employed here to allow evaluation of Konorski's hypothesis that S2 becomes associated with the neural representation of US in second-order conditioning. Extinction of responding to S1 in Group P-P-E should degrade the neural representation of US (Rescorla \& Heth, 1975), whereas it should be preserved when keypecking is eliminated through quasi-random presentations of S1 and US (Group P-P-R). According to Konorski, Group P-P-E should show a debilitation of responding to S2 in Stage 3, but Group P-P-R should respond as in Stage 1 .

\section{METHOD}

Eighteen experimentally naive White Carneaux pigeons, 6-
12 months old, were housed and maintained under the conditions described in Experiment 1 and trained in the apparatus employed there.

\section{Procedure}

First- and second-order conditioning. All but one pigeon received first- and second-order conditioning in the manner described in Group P-P in Experiment 1. The exception was assigned to Group P-P-R (see below), and it received six secondorder sessions, rather than four. This pigeon did not peck toward S2 until the fourth session, when, with responding to S1 maintained at a high level, it made rated pecks toward S2 on $30 \%$ of the trials. Two more sessions were given to allow development of responding to $S 2$. This pigeon's last four sessions' data were employed in computing means for Group P-P-R to show responding in the four sessions that $S 2$ and $S 1$ were paired. Two pigeons were dropped from the experiment after four sessions in which S2 and S1 were paired because they responded to S2 on only a few trials and showed a pronounced decrement in responding to $S 1$ across these sessions. These pigeons responded strongly to $\mathrm{S} 1$ in the alternating first-order sessions when $\$ 1$-grain pairings were given, and, consequently, they showed an "inhibitory" pattern of responding similar to that discussed for one pigeon in Group P-P in Experiment 1.

Manipulation of S1. After the last second-order session, the 16 available pigeons were assigned to two groups of five and one group of six to receive consecutive daily first-order sessions. Pigeons in Group P-P.E $(N=6)$ received first-order extinction sessions with 30 presentations of $\mathrm{SI}$ alone at a 120 -sec ITI in each session. Pigeons in Group P-P-R $(\mathbf{N}=5)$ received 30 presentations of S1 and food in each session with S1 presented every $120 \mathrm{sec}$ and food presented at variable intervals averaging $120 \mathrm{sec}$. Extinction continued for each pigeon in these groups until it met a criterion of two successive sessions with $10 \%$ or fewer trials with a rated peck to S1. Each pigeon in Group P-P-P $(\mathrm{N}=5)$ received five consecutive first-order conditioning sessions in which S1 was paired with food on each of 30 trials. Five sessions were given because pilot data had indicated that Groups P-P-E and P-P.R should reach the extinction criterion in an average of five sessions, and it was hoped to equate the three groups for number of first-order sessions between secondorder conditioning and the test session.

S2/S1 test. In the session immediately following manipulation of $\mathrm{S1}$, each pigeon was given 10 presentations of $\mathrm{S} 2$ and $\mathrm{S} 1$ to assess the ability of each stimulus to evoke keypecking. The stimuli were presented in an irregular sequence: $\mathbf{S} 2$ was presented every $120 \mathrm{sec}$ and Sl was presented at a variable ITI averaging $120 \mathrm{sec}$ (Fleshler \& Hoffman, 1962).

First-order reacquisition and $\mathbf{S 2} / \mathrm{S1}$ retest. Following the S2/S1 test, all groups received two successive first-order conditioning sessions, in each of which $\mathrm{S} 1$ and food were paired on 30 trials with a $120-\mathrm{sec}$ ITI. This training was intended to reestablish pecking to S1 for Groups P-P-E and P-P-R prior to a second test session in which $\mathrm{S} 2$ and $\mathrm{S} 1$ were presented in a quasirandom sequence, as described above.

Statistical analyses. Nonparametric statistical analyses were employed to assess between-group and within-group differences in Experiments 2, 3, and 4. In all cases, two-tailed tests were employed, except in the tests of responding to $S 2$ and $S 1$ after extinction where directional effects were expected and one-tailed tests were used.

\section{Results and Discussion}

Figure 2 shows that S2 gradually acquired control over keypecking when S2 was paired with S1. Across all three groups, the mean number of S2-S1 pairings prior to the first key contact on S2 was 14.7 , and to a criterion of three out of four successive trials with a contact on S2 was 18.5. The same pigeons required a mean $12.5 \mathrm{~S} 1$-grain pairings in first-order condi- 


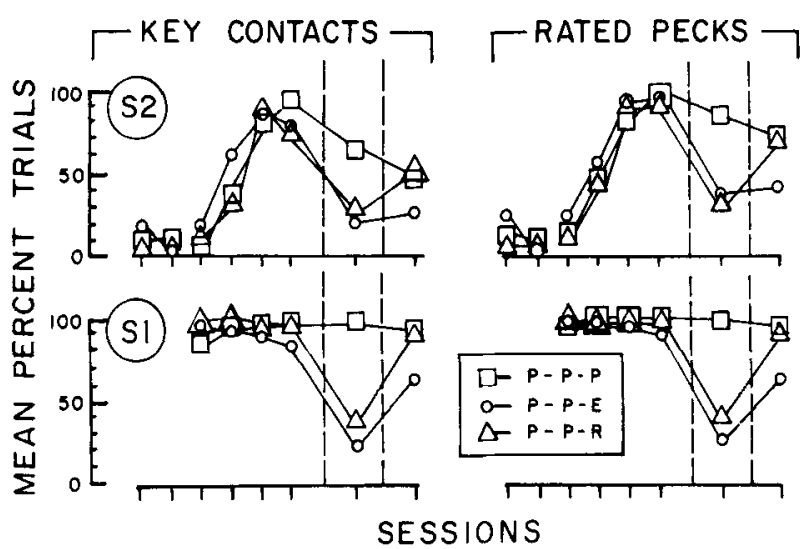

Figure 2. Mean percent trials with a key contact and rated peck on $S 2$ and $S 1$ in second-order conditioning sessions for each group in Experiment 2. The first two data points in the top panels show responding to $S 2$ in the last two sessions it was presented alone. The next four points show responding to $\mathrm{S2}$ (top) and S1 (bottom) when S2-S1 pairings were given. The points between the dotted lines in each panel show responding in the first test session. The final points in each panel show responding in the second test session. (See text for additional details.)

tioning to achieve the first trial with a peck. As in Experiment 1, these data indicate that first- and second-order conditioning proceed at the same rate in these experimental conditions. By the last secondorder session, all groups responded on about $80 \%$ of S2 presentations and did not differ significantly either in the key-contacts or the rated-pecks measure (Mann-Whitney Us $\geqslant 5.5$, ps $>.05$ ). These findings provide further evidence that second-order conditioning of the pigeon's keypeck is a robust phenomenon under our experimental conditions.

The first dotted line in each panel of Figure 2 denotes the period in which the associative strength of S1 was manipulated for two of the groups. Data from these manipulations are not shown in the figure but are summarized here. The mean number of sessions to reach the criterion of $10 \%$ or fewer trials with a response to $S 1$ in two successive sessions was 8.67 and 4.4 for Groups P-P-E and P-P-R, respectively, a difference which failed to reach statistical significance (Mann-Whitney $U=7, p>.05$ ). The minimum number of sessions for any pigeon to reach criterion was three. Responding to S1 was maintained in Group P-P-P throughout the five firstorder conditioning sessions: in the first and the fifth sessions, this group contacted S1 on $96 \%$ and $94.8 \%$ of the trials, respectively.

Data points between the dotted lines in Figure 2 show responding to $\mathrm{S} 2$ and $\mathrm{S} 1$ by each group after the intervening manipulation of S1. Mann-Whitney $\mathrm{U}$ tests confirmed that Groups P-P-E and P-P-R did not differ in percent trials with a key contact or rated peck when S2 was presented (Us $\geqslant 12.5$, ps $>.05$ ) and that both groups responded on significantly fewer trials than Group P-P-P (Us $\leqslant 2.5$, ps $<.05$ ). Between-group tests showed exactly the same pattern of significant differences in responding to $\mathrm{S} 1$. Within-group changes in responding to $S 2$ and $S 1$ between the last session of second-order conditioning and the test session were assessed with the Fisher sign test: Groups P-P-E and P-P-R showed a significant decrease in the percent of trials with either a key contact or a rated peck directed towards $\mathbf{S} 2$ or S1 (ps <.05), whereas there was no significant change in responding to $\mathrm{S} 2$ or $\mathrm{S} 1$ in Group P.P.P.

Although these data indicate that, in our version of the second-order conditioning experiment, the strength of responding to S2 depends heavily on the ability of S1 to evoke a response, three alternative accounts of the data can be reasonably proposed and rejected. The first possibility is that responding is strong to $S 2$ in the initial test trials for Groups P-P-E and P-P-R and that the apparent decrement in responding to $\mathrm{S} 2$ for these groups results from averaging across all $10 \mathrm{~S} 2$ trials in the test session. This possibility is ruled out by Wilcoxon signed-ranks tests, which showed no significant differences in responding to S2 between the firstand last-five trials of the test session for any group in either the key-contacts or rated-pecks measures (ps $>.05$ ). Comparable tests on responding to $\mathrm{S} 1$ also showed no differences. The second possibility is that high levels of responding were directed towards S2 by Groups P-P-E and P-P-R in the test but that most responses failed to activate the microswitch on the response key. It is ruled out by the similarity of the rated-pecks and key-contacts data in the test. The third possibility is that the debilitation of responding to S2 in Group P-P-E relative to Group P-P-P is due to differential extinction of background cues in the two groups, not solely because responding to $\mathrm{S} 1$ was weakened. According to this argument, extinction in Group P-P-E weakened the likelihood of responding to all stimuli, not just S1, because grain was never presented in the experimental situation. This possibility is ruled out because Groups P-P-R and P-P-P had the same number of grain and $S 1$ presentations during manipulation of $S 1$, but responding to $S 1$ was eliminated in Group P-P-R by the quasi-random presentation of $\mathrm{Sl}$ and grain. Because responding to S2 was weak in the test for both Groups P-P-E and P-P-R relative to Group P-P-P, the weakening of responding to $\mathrm{Sl}$ is clearly implicated as the factor responsible for the debilitation of responding to $\mathbf{S} 2$.

In the final portion of the experiment, responding to S1 was restored (maintained for Group P-P-P) in two first-order conditioning sessions prior to a second test session. This manipulation was carried out to determine if responding to $\mathrm{S} 2$ could be reinstated in Groups P-P-E and P-P-R without further second-order conditioning, solely by reestablishing $\mathrm{Sl}$ as an effective conditioned stimulus. The two first-order sessions were given during the period 
denoted by the second dotted line in each panel of Figure 2. Data from these sessions (not shown in the figure) indicated that all pigeons in Groups P-P-E and $\mathrm{P}-\mathrm{P}-\mathrm{R}$ rapidly reacquired the keypeck response to $\mathrm{S} 1$. In the second session, all but one pigeon contacted S1 on $93 \%$ or more of the trials, the exceptional pigeon (in Group P-P-E) contacted S1 on only $13 \%$ of trials but made rated pecks on $87 \%$ of the trials. Figure 2 shows that responding recovered to both $\mathrm{S} 1$ and $\mathrm{S} 2$ in the second test session, but that the recovery was greater for S1 than for S2. Statistical analyses confirmed that responding to S1 fully recovered to its preextinction level in the second test: responding to $\mathrm{S} 1$ in the second test and in the final second-order conditioning session did not differ for any group in the key-contacts or rated-pecks measures (Fisher sign tests, ps $>.05$ ). Despite the full recovery of responding to S1, Fisher sign tests showed that responding to $\mathrm{S} 2$ neither recovered its preextinction level in Groups P-P-E and P-P-R (ps $<.05)$ nor significantly increased between the first and second test sessions ( $\mathrm{ps}>.05$ ). Although these data demonstrate that the strength of responding to S2 failed to vary directly with the strength of responding to $\mathrm{S1}$, a finding which conflicts with the outcome of the first test, this failure may be attributed to the influence of other factors in the second test session. In particular, nonreinforced presentations of S2 in the first test may have directly extinguished responding to $S 2$, and/or the interval between second-order conditioning and the second test session may have contributed to the weakening of responding in the second test. This interpretation of the second-test data receives some support from the fact that Group P-P.P showed a nearly significant decrement in responding to $\mathrm{S} 2$ between the final second-order conditioning session and the second test $(p=.06)$. Furthermore, between-group comparisons showed no differences in responding to $\mathrm{S} 2$ in the second test session (MannWhitney Us $\geqslant 6$, ps $>.05$ ). These data suggest that the second test session is not appropriate for inferring the relationship between $\mathrm{S} 1$ and $\mathrm{S} 2$ in second-order conditioning.

Two aspects of the present results are particularly noteworthy. The first is that responding to $\mathrm{S} 2$ is debilitated equally whether responding to $S 1$ is eliminated through extinction or through uncorrelated presentations of S1 and food. This finding is not consistent with Konorski's (1948) hypothesis about associations in second-order conditioning. That hypothesis must predict weakened responding to $S 2$ in the extinction group but not in the uncorrelated group if extinction degrades the neural representation of US (Rescorla \& Heth, 1975). This finding also rules out the possibility that responding to S2 was weakened in Group P-P-E because of the extinction of background cues (see above discussion).
The second is that, in an initial test period, the strength of responding to S2 covaries with the strength of responding to S1 after second-order conditioning: keypecking to S2 was weakened when responding to S1 was weakened. This finding contrasts sharply with Rescorla's demonstrations that S2 evokes responding independently of S1 after second-order conditioning (e.g., Holland \& Rescorla, 1975a, b; Rizley \& Rescorla, 1972).

Before it can be asserted that a discrepancy truly exists between our findings and those of Rescorla, it is necessary to rule out generalization of extinction from S1 to S2 as the factor responsible for our findings. That is, S2 and S1 were from the same sense modality (visual) in our experiment, while they were from different modalities (visual, auditory) in Rescorla's experiments, thereby raising the possibility that extinction generalized from $\mathrm{S} 1$ to $\mathrm{S} 2$ in our case and overrode the normal tendency of S2 to evoke keypecking. If this could be demonstrated, the apparent discrepancy between our results and Rescorla's could be attributed to a relatively uninteresting generalization process. Our choice of stimuli as $\mathrm{S} 2$ and $\mathrm{S} 1$ was constrained by the fact that the pigeon's keypeck is not readily autoshaped to stimuli other than localized visual stimuli (e.g., Wasserman, 1972; Schwartz, 1973). The issue would be clarified best by an experiment in which the pigeon's keypeck is established to S2 through S2-S1 pairings in which $S 1$ is from a different sense modality. That procedure is employed in the next two experiments.

\section{EXPERIMENT 3}

One way to arrange second-order conditioning of the pigeon's keypeck with stimuli from two modalities is to establish discriminative-operant control over keypecking with an auditory stimulus as $\mathrm{S} 1$ and then pair a visual $\mathrm{S} 2$ with the auditory $\mathrm{S} 1$. If S2 acquires control over keypecking, appropriate control groups will indicate whether keypecking developed because S2 was paired with $\mathrm{S} 1$ and because S1 had a conditioning history, the two conditions that must be met in a well-controlled demonstration of second-order conditioning. The fact that responding to $\mathrm{S} 1$ is established with operant conditioning methodology does not invalidate the logic of the second-order experiment, although Skinner (1938, p. 258), who seriously doubted Pavlov's demonstrations of second-order conditioning, asserted that second-order conditioning would not occur if S1 was a discriminative stimulus. The present experiment successfully demonstrates second-order conditioning of the pigeon's keypeck with stimuli from two sensory modalities when $S 1$ is a discriminative stimulus. This demonstration makes it possible in Experiment 4 to employ the two-modality method- 
Table 1

Group Designations and Summary of Procedures for Experiment 3

\begin{tabular}{cll}
\hline Group Designation & \multicolumn{1}{c}{ S1 Training } & Second-Order Conditioning \\
\hline Top $-\mathrm{P}(\mathrm{N}=5)$ & tone $-\mathrm{FR} 10-$ food & blue key $\rightarrow$ tone \\
Vop-P $(\mathrm{N}=5)$ & white key - FR $10-$ food & blue key $\rightarrow$ white key \\
Top $-\mathrm{R}(\mathrm{N}=4)$ & tone $-\mathrm{FR} 10-$ food & blue key/tone (random sequence) \\
$\mathrm{TR}-\mathrm{P}(\mathrm{N}=4)$ & tone/food (random sequence) & blue key $\rightarrow$ tone \\
TP-P $(\mathrm{N}=4)$ & tone $\rightarrow$ food (each pigeon yoked & blue key $\rightarrow$ tone \\
& to a pigeon in Top-R for tone & \\
& duration and tone-food pairings) & \\
\hline
\end{tabular}

ology to examine the ability to S2 to evoke keypecking following extinction of $\mathrm{Sl}$.

\begin{abstract}
Method
Subjects and Apparatus

Twenty-two experimentally naive White Carneaux pigeons, 6-12 months old, were housed and maintained under the conditions described in Experiment 1. The apparatus employed in Experiment 1 was employed here also except that pure-tone generators were added to allow presentation of a $2,600-\mathrm{Hz}$ tone ( $80 \mathrm{~dB}$ re $20 \mu \mathrm{N} / \mathrm{m}^{2}$ ) through the same speaker that normally played white noise in each chamber. White noise was terminated in the speaker whenever tone was presented.
\end{abstract}

\section{Experimental Design}

Table 1 summarizes the conditions of this experiment. Five groups of pigeons received training with $\mathrm{S} 1$ and food before second-order conditioning sessions began. In group designations, the letters to the left of the hyphen indicate conditions during S1-training sessions where, for three of the groups, S1 was a $2,600-\mathrm{Hz}$ tone $(\mathrm{T})$ or a white keylight (V) which signaled the availability of food on a FR 10 schedule (op). In the other groups, $S 1$ and food were presented in a quasi-random sequence $(R)$ or in a forward-pairing relationship (P). The letter to the right of the hyphen describes the relation between $S 2$ and $S 1$ in secondorder conditioning sessions where S2 was either paired with S1 (P) or presented in a quasi-random sequence with S1 (R). An arrow $(\rightarrow)$ designates the temporal sequencing of events in a $P$ procedure. For example, Group Top-P received discriminativeoperant training in which a tone (S1) signaled an FR 10 keypeck requirement for food, followed by second-order training in which a blue keylight (S2) was paired with the tone; Group Vop-P received the same treatment except that a white keylight served as S1; Group TR-P received random presentations of a tone (S1) and food, followed by pairings of the blue keylight (S2) with tone during second-order conditioning.

The groups shown in Table 1 address several issues. First, Groups Top-P and Vop-P, together, will show whether S2 can acquire control over keypecking when $S 1$ is a discriminative stimulus. Second, a comparison between these two groups will indicate whether the rate or asymptote of conditioning is influenced by having $S 2$ and S1 from the same or from different modalities. Third, groups Top-R and TR-P provide the controls necesssary to demonstrate that keypecking established to $S 2$ in Group Top-P is truly second-order conditioning: that is, Groups Top-R and TR-P, respectively, will indicate whether S2-SI pairings and S1-food pairings are necessary for keypecking to be established to S2. Finally, Group TP-P will indicate whether tone-food pairings alone, without operant training, are sufficient to establish keypecking to $S 2$ when it is paired with the tone. Controls were not run for the Vop-P group because it is formally equivalent to the Top-P group in all respects except the modalities employed.

\section{Procedure}

Preliminary training. All pigeons were trained to eat from the grain hopper with the procedure described in Experiment 1. Pigeons in Group TR-P began S1 training immediately (see below), but the remaining four groups received additional preliminary training. Groups Top-P, Top-R, and Vop-P were "shaped" by the method of successive approximations to peck the key with S1 continuously present throughout the session: the response key was always illuminated red, and the $2,600-\mathrm{Hz}$ tone (i.e., S1) was continuously present for the two Top groups; the key was constantly illuminated white (i.e., S1), and white noise was always present for the Vop-P group. After "shaping," the keypeck-food contingency was gradually changed from food after each peck (FR 1) to food after every 10th peck (FR 10). Preliminary keypeck training was complete after approximately two sessions for Groups Top-P, Top-R, and Vop-P. Each pigeon in the TP-P group was yoked to a pigeon in Group Top- $\mathbf{R}$ to receive noncontingent food presentations. Stimulus conditions were the same for both groups and the yoking procedure insured that both experienced the same number and temporal distributions of grain presentations.

S1 training. After preliminary training, all pigeons received 20 consecutive sessions in which $\mathrm{Sl}$ and grain were each presented 30 times. The Top-P and Top- $\mathrm{R}$ groups received discriminative operant training in which food was available on an FR 10 schedule during 30 trial periods in each session. The pigeon was placed in a darkened chamber, and sessions began when the houselight and the red keylight were illuminated. Each trial period was $19 \mathrm{sec}$ long, although the actual events that defined the trials usually required fewer than $19 \mathrm{sec}$. The ITI did not resume until the entire trial period was complete. For the Top-P and Top-R groups, SI was the termination of white noise and simultaneous presentation of the $2,600-\mathrm{Hz}$ tone. S1 was terminated after $15 \mathrm{sec}$ or after the 10th keypeck, whichever came first. When a keypeck terminated S1, the pigeon immediately received $4-\mathrm{sec}$ access to grain in the lighted hopper. If 10 pecks failed to occur within $15 \mathrm{sec}, \mathrm{Sl}$ was terminated and the magazine was not raised on that trial. The response key was illuminated red at all times during S1 training for the two Top groups, even while the hopper was raised, so that these pigeons had no exposure to a visual stimuluschange on the response key before second-order conditioning sessions began. The minimum ITI was $120 \mathrm{sec}$ and each keypeck during the last $10 \mathrm{sec}$ of the ITI delayed the next presentation of S1 by $10 \mathrm{sec}$.

The Vop-P group received identical discriminative-operant training, except that $\mathrm{Sl}$ consisted of a change in illumination of the response key from red to white. The $2,600-\mathrm{Hz}$ tone was never presented to the Vop group and the response key was continuously illuminated red except when S1 was presented.

Each pigeon in Group TP-P was yoked to a pigeon in Group Top- $\mathrm{R}$ during discriminative training to receive the same durations of $\mathrm{S} 1$ and frequencies of S1-food pairings, irrespective of responding. Therefore, pigeons in these two groups had equivalent experience with tone and food prior to second-order conditioning, but the tone necessarily controlled keypecking only in Group Top-R. All other procedural details were held constant for the two groups.

Finally, for Group TR-P the food hopper was raised for $4 \mathrm{sec}$ every $120 \mathrm{sec}$ and a $6-\sec 2,600-\mathrm{Hz}$ tone was presented at variable intervals with a mean of $120 \mathrm{sec}$ (Fleshler \& Hoffman, 1962). This procedure was intended to prevent Sl from acquiring associative strength (Rescorla, 1967), even though the same number of tone and food presentations were given as in the Top-P and 
Top- $\mathbf{R}$ groups. The duration of the tone was $6 \mathrm{sec}$ for Group TR-P, because pilot data indicated that this duration approximated the mean length of tone per trial for a Top group. The response key was continuously illuminated red for Group TR-P.

Dependent variables during discriminative operant training were rate of keypecks during the ITI and during S1, and the percentage of trials per session with at least one key contact. Discrimination ratios were computed for each session by the formula: rate during $\mathrm{Sl}$ (rate during $\mathrm{S} 1+$ rate during ITI). Therefore, discriminative control of keypecking by $\mathrm{S} 1$ is evidenced by discrimination ratios greater than 0.5 .

Second-order conditioning. After the 20 th consecutive session of S1 training, second-order sessions occurred on odd-numbered days throughout the rest of the experiment. On even-numbered days, each group received S1 training as described above. Each pigeon initially received sessions in which $\mathrm{S} 2$ was presented alone until a criterion of two successive sessions with $10 \%$ or fewer trials with a rated peck to $S 2$ was met. For all groups, the response key was illuminated red during the $120-\mathrm{sec} I \mathrm{TI}$ and $\mathrm{S} 2$ was a 6 -sec change in illumination of the key from red to blue. Keypecks had no programmed consequences at any time in second-order sessions. After keypecking to $\mathbf{S} 2$ reached criterion, each pigeon received four second-order sessions in which S2 and S1 were each presented 10 times. S2 and S1 each were $6 \mathrm{sec}$ in duration, and S1 was tone or keylight, as required for the various groups. All but Group Top-R received S2-S1 pairings in second-order conditioning at a 120-sec ITI. For Group Top-R, S1 was presented every $120 \mathrm{sec}$ and $\mathrm{S} 2$ was presented on a variable schedule with a mean of $120 \mathrm{sec}$ (Fleshler \& Hoffman, 1962). The response key was illuminated red at all times during second-order sessions except when S2 was presented, or when the visual S1 was presented for the Vop-P group. Grain was never presented in second-order sessions.

\section{Results and Discussion}

In discriminative-operant training, the discrimination ratio for Group Vop-P was above 0.9 from the first session of training, but required from five to seven sessions to reach that level for Groups Top-P and Top-R. These data indicate that the white keylight acquired control over keypecking more rapidly than did the $2,600-\mathrm{Hz}$ tone. In Sessions 11 through 20 , however, the discrimination ratio never fell below 0.9 for any group and the mean percent trials with a key contact was $99.8,99.9$, and 99.6 for Groups Top-P, Vop-P, and Top- $\mathrm{R}$, respectively. The mean tone duration per trial computed over all pigeons in both Top groups on the last 5 days of discriminativeoperant training was $5 \mathrm{sec}$. In the Vop group, the comparable statistic was $3.7 \mathrm{sec}$. In these groups, FR 10 was completed on virtually every trial by the end of training. Very few keypecks were recorded during the tone or the ITI for Groups TP-P and TR-P in the first 20 sessions when S1 and grain were presented. Informal observations indicated that all pigeons in Group TP-P made pecking movements in and around the hopper area when S1 was presented, but not during the ITI. It is unlikely that hopperpecking movements in Group TP-P were directed toward the speaker because it was not mounted directly behind the hopper and because construction of the test chamber made it unlikely that the tone was well localized. Thus, before second-order conditioning sessions began, S1 reliably evoked key- pecking in Groups Top-P, Top-R, and Vop-P, but not in Groups TR-P or TP-P. In the latter group, however, S1 evoked pecking in the grain hopper.

When S2 was presented alone, the mean sessions to a criterion of two successive sessions with $10 \%$ fewer trials with a rated peck was 4.2,6.0, and 3.25 for Groups Top-P, Vop-P, and Top-R, respectively. Differences among these groups were not statistically significant (Mann-Whitney Us $\geqslant 3$, ps > .05), indicating that under the conditions of this experiment, at least, keypecking evoked by $\mathrm{S} 2$ in the S2-alone sessions cannot be attributed solely to within-modality generalization from S1. Groups TP-P and TR-P, for which Sl did not evoke keypecking, reached criterion in a mean 2.0 and 2.3 S2-alone sessions, respectively. Each of the latter groups required significantly fewer sessions to reach criterion than Groups Top-P and Vop-P (Mann-Whitney Us $\leqslant 1$, ps $\leqslant .05)$, but did not differ from Group Top-R (Us $\geqslant 2$, ps $>.05)$.

Figure 3 shows responding to $\mathrm{S} 2$ and $\mathrm{S} 1$ in secondorder conditioning sessions for all groups. The first two data points on the upper panels are from the last two sessions in which S2 was presented alone. The remaining data points in these panels show that there was a gradual acquisition of keypecking to $\mathrm{S} 2$ across four sessions in Groups Vop-P and Top-P. The first key contact on S2 occurred after means of 16 and 10.2 trials, respectively, for Groups Top-P and Vop-P; three out of four successive trials with a contact occurred after 21.4 and 12.2 trials, respectively, for the two groups. No between-group differences reached statistical significance (MannWhitney Us $\geqslant 6$, ps $>.05$ ). Although it appears that acquisition was faster in Group Vop-P than in Top-P, the differences are attributable to the responding of two of the five pigeons in the Vop-P group. In the fourth second-order session, pigeons in Groups Top-P and Vop-P were contacting S2 on an average of $70 \%$ and $56 \%$ of the trials, respectively, and rated pecks were scored on $76 \%$ of the trials for both groups. Differences between the groups were never statistically significant in the key-contact or rated-pecks measures (Mann-Whitney Us $\geqslant 4.5$, ps $>$.05). Therefore, neither the rate of development nor the final level of keypecking to the visual S2 was significantly affected by whether S1 was from the visual or auditory modality. Figure 3 shows that S2 failed to acquire control over keypecking in Groups Top-R and TR-P, indicating that keypecking developed to S2 in Group Top-P because S2 was paired with $\mathrm{S} 1$ and because $\mathrm{S} 1$ had a conditioning history. Taken together, then, these findings provide a well-controlled demonstration of secondorder conditioning of the pigeon's keypeck with stimuli from two modalities and, along with the data of Group Vop-P, show that second-order conditioning can occur when S1 is a discriminative stimulus (cf. Skinner, 1938, p. 258). 


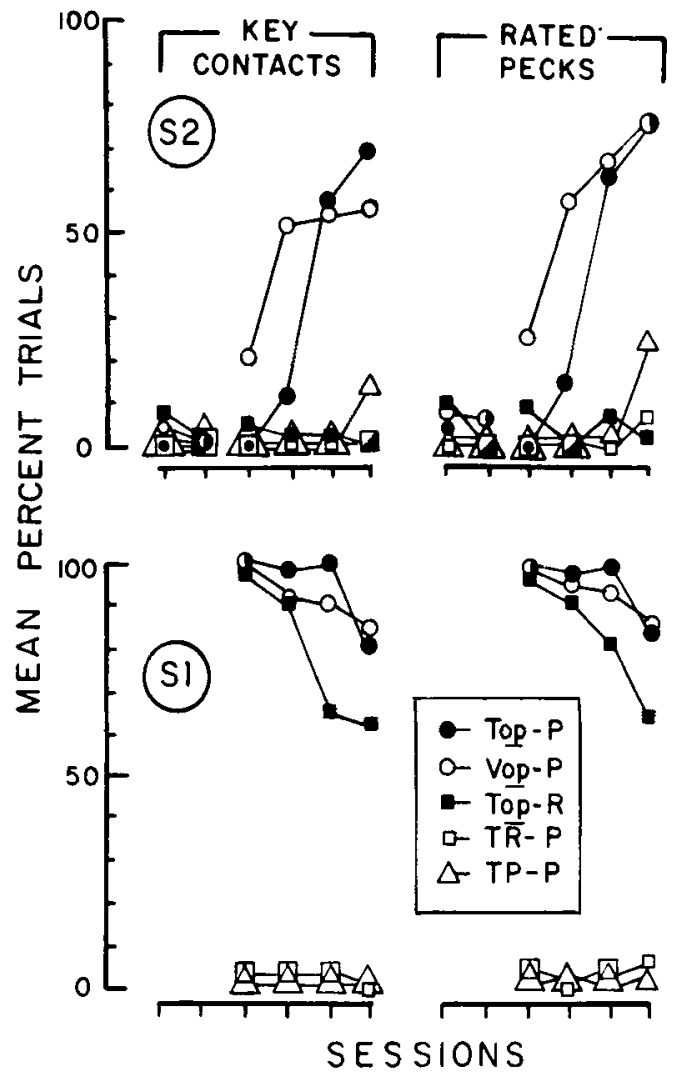

Figure 3. Mean percent trials with a key contact and rated peck on $S 2$ and $S 1$ in second-order conditioning sessions for each group in Experiment 3. (See text for details.)

Figure 3 shows a small increase in keypecking to S2 by Group TP-P in the fourth second-order session. This increase was entirely due to the acquisition of keypecking by one pigeon, and it suggested that second-order conditioning of the keypeck might appear late in this group. Therefore, this one pigeon received two additional second-order sessions and the three remaining pigeons received four more secondorder sessions (not shown in Figure 3). S2 reliably evoked keypecking in only two of these four pigeons during the additional sessions. These results indicate that S1 need not evoke keypecking to be effective in second-order conditioning, although S2 seems to acquire control over keypecking more rapidly and with greater reliability when S1 evokes keypecking. It is not possible to determine here whether S1 must evoke pecking (e.g., in the grain hopper), as was the case in Group TP-P, to be effective in establishing keypecking to S2 in second-order conditioning or whether it need only be paired with grain. The essential factor may be that $S 1$ has been paired with a US such as food (cf. Gamzu \& Williams, 1975; Holland \& Rescorla, 1975a, b; Patterson \& Winokur, 1973; Zentall \& Hogan, 1975), not that it evokes a response. If this turns out to be the case, it is not readily accommodated by a literal interpretation of the hypothesis that an S-R association is formed between $\mathrm{S} 2$ and the response evoked by $\mathrm{S} 1$ in second- order conditioning (Rescorla, 1973a) or by the hypothesis that an S-S association is formed.

Finally, no significant differences were found between Groups Top-P, Vop-P, and Top-R in responding to $\mathrm{S} 1$ during second-order sessions (Mann-Whitney Us $\geqslant 2.5$, ps $>.05$ ). The apparent decrease in responding to $\mathrm{S} 1$ by Group Top-R across sessions was due to one pigeon whose response levels decreased in the third and fourth sessions. In Group TP-P, all pigeons continued to make pecking movements in the hopper area during S1.

In summary, Experiment 3 conclusively demonstrates second-order conditioning of the pigeon's keypeck when $\mathrm{Sl}$ is a discriminative stimulus for keypecking and, in some cases, when S1 does not control keypecking. Acquisition of keypecking to S2 occurred equally fast whether S1 and S2 were from the same or from different sensory modalities.

\section{EXPERIMENT 4}

This experiment investigated whether extinction of responding to $\mathrm{S} 1$ debilitates responding to $\mathrm{S} 2$ when $\mathrm{S} 2$ and $\mathrm{S} 1$ are from different sense modalities. A visual S2 was made a second-order conditioned stimulus in two groups by pairing it with an auditory S1 that was a discriminative stimulus for keypecking. Responding to S1 was then extinguished in one group but maintained in the other. Finally, S2 and S1 were presented to both groups in test sessions. A third group received second-order conditioning and extinction of S1 with visual stimuli as S2 and S1. If within-modality generalization of extinction was the factor responsible for the debilitation of responding to S2 in Experiment 2, in the present experiment only that group with visual stimuli as $\mathrm{S} 2$ and $\mathrm{S} 1$ should show a decrement in responding to $\mathrm{S} 2$ when it is tested after extinction of S1.

\section{Subjects and Apparatus \\ Method \\ Five experimentally naive White Carneaux pigeons and 10 pigeons carried over from Experiment 3 were maintained and housed as described in Experiment 1 . The 10 carry-over pigeons had comprised Groups Top-P and Vop-P in Experiment 3. The 5 new pigeons received exactly the same treatment as Group Top-P in Experiment 3 prior to the manipulation of $S 1$ in the present experiment. The same apparatus was employed as in the third experiment.}

\section{Procedure}

Beginning in the session immediately after second-order conditioning was complete (see Results), pecking to SI was extinguished in Groups Vop-P-E and Top-P-E (formerly Groups Vop-P and Top-P in Experiment 3). Each pigeon received consecutive daily sessions of 30 6-sec presentations of the appropriate discriminative stimulus (white keylight or tone) at a 120-sec ITI until a criterion of $10 \%$ or fewer trials with a rated peck on 2 consecutive days was met. Group Top-P-P received discriminative operant training with $\mathrm{S} 1$ for seven consecutive sessions after second-order conditioning. Pilot data indicated a mean of 7 days would be required by Group Top-P-E to meet the extinction criterion, and it was 
intended that the Top-P-E and Top-P-P groups be tested with S2 after approximately the same number of sessions without exposure to S2. During these sessions, each keypeck in the last $10 \mathrm{sec}$ of the ITI delayed the next presentation of S1 by $10 \mathrm{sec}$ for all groups.

An S2 test consisting of $106-\mathrm{sec}$ presentations of $\$ 2$ at a $120-\mathrm{sec}$ ITI was given on the day after each pigeon completed extinction (Groups Top-P-E and Vop-P-E) or after the seventh session of discriminative-operant training (Group Top-P-P). An S1 test was given on the following day in which 10 6-sec presentations of S1 were presented at a $120-\mathrm{sec}$ ITI.

\section{Results and Discussion}

Acquisition of second-order conditioning of keypecking in Group Top-P-P is shown in Figure 4, along with the data of Groups Top-P-E and Vop-P-E replotted from Experiment 3. The Top-P-P group acquired responding to $\mathrm{S} 2$ at about the same rate as Group Top-P-E: in the fourth second-order session, mean percent trials with a contact on S2 was $60 \%$, and with a rated peck was $66 \%$. At no time during second-order conditioning sessions did Groups Top-P-E, Vop-P-E, and Top-P-P differ significantly in percent trials with a key contact or rated peck to $\mathrm{S} 2$ (Mann-Whitney $\mathrm{Us} \geqslant 3$, ps $>.05$ ). Because responding to $\mathrm{S} 2$ was low in some pigeons in the fourth second-order session (one pigeon in Group Top-P-E and two in Group Top-P-P), these pigeons were given a fifth session of second-order conditioning (not shown in Figure 4) in an attempt to strengthen responding to $\mathrm{S} 2$ before manipulation of S1 began. When the additional session's data were combined with the fourth-session data for the other pigeons, the percent trials with a contact on $\mathrm{S} 2$ in the session before responding to $\mathrm{S} 1$ was manipulated was $74 \%$ and $80 \%$ for Groups Top-P-E and Top-P-P, respectively. Comparable rated-peck statistics were $80 \%$ and $90 \%$ for the two groups.

The vertical dashed line in each panel of Figure 4 indicates the period in which $\mathrm{S} 1$ was extinguished for Groups Top-P-E and Vop-P-E while Group Top-P-P received continued discriminativeoperant training. The Top-P-E and Vop-P-E groups, respectively, required a mean 6.8 and 10 sessions to reach the extinction criterion, not a statistically significant difference (Mann-Whitney $U=8, p>.05$ ). Group Top-P-P continued to respond on every S1 trial throughout the seven sessions of discriminativeoperant training. Data for these sessions are not shown in Figure 4.

S2- and S1-test results are shown on the right side of the dashed lines in Figure 4. Groups Top-P-E and Vop-P-E contacted S2 on a mean $24 \%$ and $8 \%$ of the trials, respectively, during the test session, while Top-P-P averaged $60 \%$ of the trials with a key contact. Mann-Whitney $U$ tests indicated that the Top-P-E and Vop-P-E groups did not differ from one another on this measure $(U=8, p>.05)$, and that both pecked on significantly fewer $\mathrm{S} 2$ presentations than Group Top-P-P (Us $\leqslant 4$, ps $<.05$ ). The

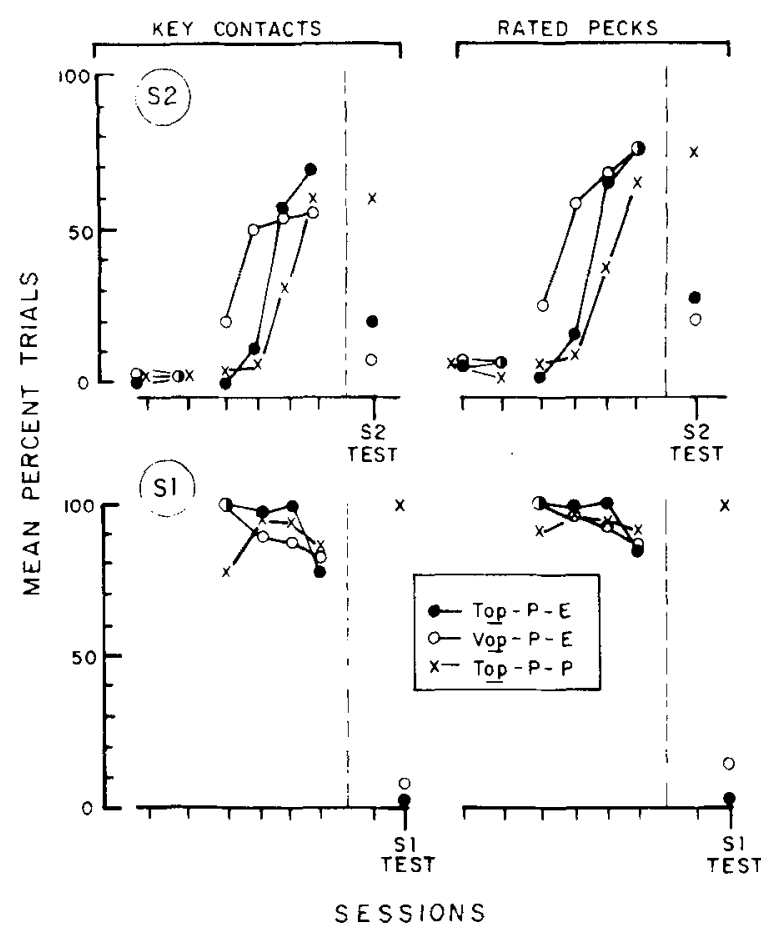

Figure 4. Mean percent trials with a key contact and rated peck on S2 and S1 in second-order conditioning sessions for each group in Experiment 4. (See text for details).

rated-pecks measure was slightly higher for all groups in the $\mathrm{S} 2$ test, but the relationships among the groups and the statistical significance of the differences was the same as in the key-contact measure. As in Experiment 2, there was no statistical difference between responding on Trials 1-5 and Trials 6-10 of the test session, indicating that the S2-test results in Figure 4 are not an artifact of averaging across all 10 test trials. The S1-test data, shown in the bottom panels of Eigure 4, confirm that keypecking to $\mathrm{S} 1$ was reduced by extinction in Groups Top-P-E and Vop-P-E. There was no significant difference between responding to $S 2$ and $\mathrm{Sl}$ in the test sessions for either Group Top-P-E or Group Vop-P-E in the key-contacts and ratedpecks measures (Fisher sign test, ps $>.18$ ).

This experiment demonstrates that responding to a visual $S 2$ is equally debiiitated by extinction of an auditory or visual S1 and, consequently, supports the claim that within-modality generalization of extinction from $\mathrm{S} 1$ to $\mathrm{S} 2$ is not sufficient to account for the debilitation of keypecking to $\mathrm{S} 2$ found after keypecking to $\mathrm{S} 1$ is weakened.

\section{GENERAL DISCUSSION}

The present experiments establish two major points. The first is that the pigeon's keypeck is susceptible to second-order conditioning. The second is that the ability of the second-order conditioned stimulus to evoke keypecking is markedly reduced 
following extinction of the first-order conditioned stimulus. Implications of these findings are discussed below.

Our successful demonstration of second-order conditioning of the pigeon's keypeck adds to the growing body of evidence that second-order conditioning is a robust phenomenon in a variety of response systems (e.g., Holland \& Rescorla, 1975a, b; Rescorla, 1973a; Rizley \& Rescorla, 1972). Our experiments are unique in showing that directedmotor action is susceptible to second-order conditioning, and this may have important implications for theoretical analyses of conditioned reinforcement in instrumental training. In many studies of conditioned reinforcement, the instrumental responsereinforcer contingency insures that an animal is exposed to some localized stimulus (e.g., a response key, a lever, an arm of a T-maze) just before it is exposed to a conditioned stimulus (i.e., the conditioned reinforcer), and the observed result is an increase in the strength of motor behavior directed towards the localized stimulus (e.g., Hendry, 1969; Wike, 1966). The increased strength of motor behavior in these experiments has traditionally been attributed to the reinforcing effect of the conditioned stimulus on the response which preceded it. The present data suggest a new possibility: at least part of the strength of motor behavior attributed to the instrumental response-conditioned stimulus contingency may, in fact, derive from second-order conditioning. The present experiments suggest this possibility because they clearly demonstrate that localized stimuli acquire control over approach and contact responses when they are repeatedly paired with an already-conditioned stimulus. Moore (1973) proposed that first-order classical conditioning may be sufficient to explain much of the behavior produced in instrumental training with primary reinforcers. The present proposal extends Moore's logic to instrumental training in which conditioned reinforcers are employed.

It is possible that conditioned reinforcement accounts for second-order conditioning, rather than that second-order conditioning accounts for conditioned reinforcement as proposed above. That is, responding to $\mathrm{S} 2$ may be strengthened by adventitious conjunctions of responses and $\mathrm{S} 1$, in which case S1 would act as an instrumental conditioned reinforcer. The appropriate experimental technique for evaluating the role of adventitious reinforcement in classical conditioning is omission training (Sheffield, 1965). In second-order conditioning of the pigeon's keypeck, omission training would allow S2-S1 pairings only on those trials when a keypeck was not made to S2. Because S1 would be omitted on trials when S2 evoked a peck, there could never be an adventitious conjunction of keypecks and S1. The acquisition of control over keypecking by S2 despite an omission procedure would defy an adventitious-reinforcement interpretation. Although omission training has yet to be carried out in experiments on second-order conditioning of directed motor action, it seems relatively improbable that adventitious reinforcement will prove to be of major importance. For one thing, it appears to play a relatively minor role in first-order conditioning of the pigeon's keypeck (e.g., Williams \& Williams, 1969), a fact verified under the present experimental conditions (Griffin \& Rashotte, 1973). For another, conditioned reinforcement might not be expected to exert as great an effect on responding as primary reinforcement.

It should be recognized that in the present experiments a blue keylight always served as S2 and, when two visual stimuli were employed, a white keylight served as S1. Rashotte and Griffin (Note 1) ran 12 pigeons in a P-P condition with key colors reversed and found that acquisition of responding to $\mathrm{S} 2$ occurred as readily as in the present experiments, except that there was a higher frequency of offkeypecking when the white keylight served as S2. They also found responding to S2 to be markedly debilitated by extinction of responding to S1. These findings indicate that the conclusions of the present experiments are not limited to the specific stimuli employed here as S2 and S1.

Finally, it is important to note that the role of experimental parameters in second-order conditioning of the pigeon's keypeck remains to be explored. Our present procedure of running 20 firstorder conditioning sessions (600 S1-grain pairings) prior to beginning second-order conditioning, of alternating first- and second-order sessions, and of employing 120-sec ITIs was arrived at fortuitously. It remains to be seen whether other values of these parameters will affect the strength of second-order conditioning. One parameter known to be important in our experiments is the number of S2-S1 trials in second-order sessions. Griffin and Rashotte (Note 2) found that responding to S2 and S1 declined across trials within second-order sessions when 30 S2-S1 pairings were given. Responding to both stimuli was strong in the first 10 or so trials of each session, however, indicating the involvement of some transient factors, perhaps inhibition. This possibility remains to be explored, as does the related issue of the durability of responding to both S2 and S1 during an extended number of second-order conditioning sessions. Investigations of these issues may clarify why S2 came to evoke keypecking in most pigeons in these experiments but possibly became a conditioned inhibitor in some. It also remains to be determined whether directed motor action is readily susceptible to second-order conditioning in other species. Directed motor action has been conditioned in a variety of species with the method of first-order 
conditioning (e.g., Hearst \& Jenkins, 1974), but there appear to be some important exceptions. For example, Stepien (1974) summarized a number of experiments in which intact dogs and cats failed to approach and contact a localized signal for food, but those with prefrontal lesions or ablations readily did so (but see Grastyán and Vereczkei, 1974, for conflicting data with cats).

The second major finding in the present experiments was that after second-order conditioning extinction of keypecking to SI markedly affects the ability of S2 to evoke keypecks, whether S1 and S2 are from the same or from different sense modalities. This finding cannot easily be attributed to stimulus generalization and, therefore, it appears to represent a genuine exception to Rescorla's claim that S2 and $\mathrm{Sl}$ are independent after second-order conditioning. Rescorla's experiments have employed conditioned-suppression or conditioned-activity procedures to study second-order conditioning in rats (e.g., Holland \& Rescorla, 1975a, b; Rizley \& Rescorla, 1972). In Rizley and Rescorla's experiments, for example, the index of conditioning was suppression of leverpressing and, in their Experiment 2, a light (S2) came to evoke suppression after a few pairings with tone (S1) which already did so because of previous tone-shock pairings. Successive $\mathrm{S} 1$-alone trials were then given to extinguish $\mathrm{S} 1$, and in subsequent test sessions S2 was found to evoke suppression while S1 did not. This latter finding suggests that $S 2$ and $S 1$ are independent after secondorder conditioning, and it and others from Rescorla's laboratory have provided the empirical basis for proposing that second-order conditioning involves S-R associations (e.g., Rescorla, 1973a; cf. Rozeboom, 1958). Following Rozeboom's (1958) logic, the present experiments challenge the generality of Rescorla's proposal that an S-R association between $\mathrm{S} 2$ and the response evoked by $\mathrm{S} 1$ is formed in second-order conditioning. Rather, an S-S association between $S 2$ and $S 1$ is required by the present data, thereby implicating the same associative process in second-order conditioning as is widely acknowledged to underlie first-order conditioning (e.g., Rescorla, 1973a).

Obvious variables might account for the discrepancy between our results and those of Rescorla. For example, species differences may be involved (pigeons vs rats), or differences in the homogeneity of proprioceptive feedback from the conditioned responses (relatively homogeneous feedback in our experiments where all responses were directed towards highly localized stimuli vs relatively heterogeneous feedback in Rescorla's experiments where responses were the absence of bar-pressing or the occurrence of movements in an activity cage). At the present time, however, it seems more likely that certain procedural differences may be crucial. For one thing, in Rescorla's experiments, it is possible that $\mathrm{S} 2$ is effective after S1 has been extinguished because extinction was carried out under conditions discriminably different from those in which S2 and Sl were established as conditioned stimuli. In all of Rescorla's experiments (Holland \& Rescorla, 1975a; Rescorla, 1973b; Rizley \& Rescorla, 1972), firstand second-order conditioning and the postextinction test of S2 were carried out with relatively long ITIs, whereas short ITIs were employed both in extinction and in subsequent postextinction tests in which $\mathrm{S} 1$ was presented alone. If trial-spacing acts as a discriminative stimulus, the conflict between our results and Rescorla's would be resolved because we maintained the same ITI in all phases of our experiments. In that case, our result provides a clearer picture of the relation between S2 and S1 in second-order conditioning.

Another reason for the conflicting results may lie in the amount of extinction given before $S 2$ is tested. In our experiments, each pigeon was tested only after it reached a criterion of low responding to $\mathrm{S} 1$ in two successive sessions; in Rescorla's experiments, all rats were given a fixed number of extinction trials, raising the possibility that extinction was not complete in some animals. The interpretation of some of Rescorla's data is further complicated by evidence that in the conditioned-suppression experiment, at least, a first-order CS which no longer evokes suppression of leverpressing after an extensive history of extinction can be shown to retain considerable conditioned strength when tested in a more sensitive way, such as in a compound (Reberg, 1972). Rescorla (Holland \& Rescorla, 1975a; Rescorla, Note 3) has proposed that second-order conditioning may provide a sensitive test for showing that a firstorder CS has associative strength, even though that CS may not reliably evoke a conditioned response when presented alone. Accepting this proposal, it follows that S2 may evoke suppression after S1 no longer does so because $\mathrm{Sl}$ retains associative strength which cannot be detected when $\mathrm{S} 1$ is presented alone. In that case, Rescorla's suppression experiments would be best interpreted as evidence of an S-S association in second-order conditioning, the conclusion suggested by the present results. In one experiment on conditioned activity, Holland and Rescorla (1975a, Experiment 2) paired the extinguished S1 with a new stimulus, S3, to determine whether S1 had sufficient residual associative strength to allow $S 3$ to become a second-order conditioned stimulus. The outcome of this procedure is sketchily reported, but $\mathrm{S} 1$ seems to have conditioned a small amount of activity to S3. Clearly, more thorough assessment of the associative status of $\mathrm{S} 1$ after extinction is necessary before it can be asserted that the ability of S2 to evoke a 
conditioned response after extinction of $\mathrm{S} 1$ is evidence that $\mathrm{S}-\mathrm{R}$ associations form in second-order conditioning.

Despite theoretical uncertainties about associative processes in second-order conditioning, there is no doubt that its empirical status has become much more secure in recent years (Rescorla, 1973a). The present experiments contribute a new dimension to this empirical base by showing that directed motor action is susceptible to second-order conditioning. In view of the fact that second-order conditioning has been invoked by theorists to explain phenomena as diverse as conditioned reinforcement (Hull, 1943) and the content of dreams (Frolov, 1937, p. 163ff), it can be hoped that the large assortment of experimental techniques now available for its study will bring some new insights into this important conditioning phenomenon.

\section{REFERENCE NOTES}

1. Rashotte, M. E., \& Griffin, R. W. Second-order appetitive conditioning in the pigeon. Paper presented at the meeting of the Psychonomic Society. Boston, November 1974.

2. Griffin, R. W., \& Rashotte, M. E. Higher-order conditioning of stimulus-directed pecking in pigeons. Paper presented at the meeting of the Southeastern Psychological Association, Hollywood, Florida, May 1974.

3. Rescorla, R. A. Second-order conditioning. Invited address to the meeting of the Midwestern Psychological Association, Chicago, May 1976.

\section{REFERENCES}

Barrera, F. J. Centrifugal selection of signal-directed pecking. Joumal of the Experimental Analysis of Behavior, 1974, 22, 341-355.

Brown, P. L., \& Jenkins, H. M. Auto-shaping of the pigeon's keypeck. Journal of the Experimental Analysis of Behavior, 1968, 11, 1-8.

Ferster, C. B., \& Skinner, B. F. Schedules of reinforcement. New York: Appleton-Century-Crofts, 1957.

Fleshler, M., \& Hoffman, H. S. A progression for generating variable interval schedules. Journal of the Experimental Anulysis of Behavior, 1962, 5, 529-530.

Frolov, Y. P. Pavlov and his school. New York: Oxford University Press, 1937.

Gamzu, E., \& Williams, D. R. The source of keypecking in autoshaping. Animal Learning \& Behavior, 1975, 3, 37-42.

GRASTYÁN, E., \& VERECZKEI, L. Effects of spatial separation of the conditioned signal from the reinforcement: A demonstration of the conditioned character of the orienting response or the orientational character of conditioning. Behavioral Biology, 1974. 10, 121-146.

Griffin, R. W., \& Rashotte, M. E. A note on the negative automaintenance procedure. Bulletin of the Psychonomic Society, 1973, 1, 178-180.

Hearst, E., \& Jenkins, H. M. Sign-tracking. Austin: Psychonomic Society, 1974.

HendRY, D. P. (Ed.) Conditioned reinforcement. Homewood: Dorsey Press, 1969.
Holland, P. C., \& Rescorla, R. A. Second-order conditioning with food unconditioned stimulus. Journal of Comparative and Physiological Psychology, 1975, 88. 459-467. (a)

Holland, P. C., \& Rescorla, R. A. The effect of two ways of devaluing the unconditioned stimulus after first- and secondorder appetitive conditioning. Joumal of Experimental Psychology: Animal Behavior Processes, 1975, 1, 355-363. (b)

Hull, C. L. Principles of behavior. New York: Appleton-CenturyCrofts, 1943.

KonoRski, J. Conditioned reflexes and neuron organization. London: Cambridge University Press, 1948.

Moore, B. R. The role of directed Pavlovian reactions in simple instrumental learning in the pigeon. In R. A. Hinde \& J. Stevenson-Hinde (Eds.), Constraints on learning. London: Academic Press, 1973.

Patterson, D. D., \& Winokur. S. Autoshaping pigeons' keypecking with a conditioned reinforcer. Bulletin of the Psychonomic Society, 1973, 1. 247-249.

Pavlov, I. P. Conditioned reflexes. London: Oxford University Press, 1927.

RAzRAN. G. A note on second-order conditioning-and secondary reinforcement. Psychological Review, 1955, 62, 327-332.

REBERG, D. Compound tests for excitation in early acquisition and after prolonged extinction of conditioned suppression. Learning and Motivation, 1972, 3, 246-258.

Rescorla, R. A. Pavlovian conditioning and its proper control procedures. Psychological Revien', 1\%7, 74. 71-80.

Rescorla, R. A. Pavlovian conditioned inhibition. Psychological Bulletin, 1969, 72, 77.94.

Rescorla, R. A. Second-order conditioning: Implications for theories of learning. In F. J. McGuigan \& D. B. Lumsden (Eds.), Contemporary approaches to conditioning and learning. New York: Wiley, 1973. (a)

RESCORLA. R. A. Effect of US habituation following conditioning. Journal of Comparative and Physiological Psychology, 1973, 82. 137-143. (b)

Rescorla, R. A., \& Heth, C. D. Reinstatement of fear to an extinguished conditioned stimulus. Journal of Experimental Psychology: Animal Behavior Processes, 1975, 1, 88-96.

Rizley, R. C., \& Rescorla, R. A. Associations in second-order conditioning and in sensory preconditioning. Journal of Comparative and Physiological Psychology, 1972, 81, 1-11.

Rozeвоoм, W. W. "What is learned?"-An empirical enigma. Psychological Bulletin, 1958, 65, 22-33.

SchwARTz, B. Maintenance of key pecking by response-independent food presentation: The role of the modality of the signal for food. Journal of the Experimental A nalysis of Behavior, 1973, 20, $17-22$.

ShefFIELd, F. D. Relations between classical conditioning and instrumental learning. In W. F. Prokasy (Ed.), Classical conditioning. New York: Appleton-Century-Crofts, 1965.

SkINner, B. F. The behavior of organisms. New York: AppletonCentury-Crofts, 1938.

Stepień, I. The magnet reaction, a symptom of prefrontal ablation. Acta Neurobiologica Experimentalis, i974, 34, 145-160.

WASSERMAN, E. A. Auto-shaping: The selection and direction of behavior by predictive stimuli. Unpublished doctoral dissertation. Indiana University, 1972.

WIKE, E. L. Secondary reinforcement. New York: Harper \& Row, 1966.

Williams, D. R., \& Williams, H. Auto-maintenance in the pigeon: Sustained pecking despite contingent non-reinforcement. Journal of the Experimental A nalysis of Behavior, 1969, 12, $511-520$.

Zentall. T. R., \& Hogan, D. E. Key pecking in pigeons produced by pairing keylight with in accessible grain. Journal of the Experimental Analysis of Behavior, 1975, 23, 199-206.

(Received for publication June 22, 1976; revision accepted July 22,1976 .) 